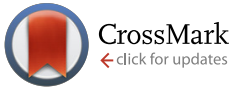

Cite this: Catal. Sci. Technol., 2016, 6,5801

Received 25th April 2016, Accepted 24th June 2016

DOI: 10.1039/c6cy00899b

\section{Selective hydrogenation of arenes to cyclohexanes in water catalyzed by chitin- supported ruthenium nanoparticles $\dagger$}

\author{
Yuna Morioka, ${ }^{a}$ Aki Matsuoka, ${ }^{a}$ Kellie Binder, ${ }^{b}$ Benjamin R. Knappett, ${ }^{b}$ \\ Andrew E. H. Wheatley*b and Hiroshi Naka*a
}

www.rsc.org/catalysis

The selective hydrogenation of aromatic compounds to cyclohexanes was found to be promoted by chitin-supported ruthenium nanoparticles (Ru/chitin) under near-neutral, aqueous conditions without the loss of $\mathrm{C}-\mathrm{O} / \mathrm{C}-\mathrm{N}$ linkages at benzylic positions.

The catalytic hydrogenation of arenes is a straightforward and hugely important method by which cyclohexanes are produced., ${ }^{1,2}$ However, a major issue with this transformation is the need to suppress the competitive hydrogenolysis of reactive carbon-heteroatom linkages (e.g. $\mathrm{C}-\mathrm{O}$ and $\mathrm{C}-\mathrm{N}$ bonds) at benzylic positions. ${ }^{3,4}$ Attempts to address this problem typically focus on using acetic acid as a (co-)solvent in the presence of late transition metal catalysts such as $\mathrm{PtO}_{2},{ }^{5 a}$, ${ }^{b} \mathrm{Rh}-\mathrm{PtO}_{2},{ }^{5 c} \mathrm{RuO}_{2},{ }^{6 a} \mathrm{Ru} / \mathrm{Al}_{2} \mathrm{O}_{3}{ }^{6 b}$ and $\mathrm{Rh} / \mathrm{Al}_{2} \mathrm{O}_{3} .{ }^{7}$ The most frequently used catalysts are $\mathrm{Ru} / \mathrm{Al}_{2} \mathrm{O}_{3}$ or, substantially more expensive, $\mathrm{Rh} / \mathrm{Al}_{2} \mathrm{O}_{3}$. However, irrespective of the choice of catalyst, the use of acidic reaction media is incompatible with substrates bearing acid-sensitive functionalities such as epoxides and tertiary benzylic alcohols. Recently studied catalysts that have allowed the selective arene hydrogenation of benzyl alcohols or ethers in the absence of acidic additives include $\mathrm{Rh} / \mathrm{AlO}(\mathrm{OH}),{ }^{8}{ }^{a} \mathrm{Ru} / \mathrm{MCM}-41,{ }^{8 b} \mathrm{Ru} / \mathrm{CNF}-\mathrm{P},{ }^{9 a, b} \mathrm{Rh} / \mathrm{CNF}^{2}{ }^{9 c}$ and $\mathrm{Ru} / \mathrm{HPS}-\mathrm{NR}_{3} \mathrm{Cl}^{9}{ }^{9}$ In particular, Motoyama and Nagashima elegantly demonstrated the simultaneous tolerance of epoxide and benzylic $\mathrm{C}-\mathrm{O}$ functionalities using $\mathrm{Rh} / \mathrm{CNF}-\mathrm{T}$ or $\mathrm{Ru} / \mathrm{HPS}-$ $\mathrm{NR}_{3} \mathrm{Cl} .{ }^{9 c, d}$ However, with the exception of the $\mathrm{Ru} / \mathrm{HPS}-\mathrm{NR}_{3} \mathrm{Cl}$ system, which utilized $\mathrm{H}_{2} \mathrm{O}$ as a solvent, ${ }^{9 d}$ these reactions were typically run in hydrocarbons or polyethylene glycol. ${ }^{10,11}$ The development of catalytic systems that operate under aqueous conditions remains strongly in demand, since it promises a route to functionalized, water-soluble cyclohex-

\footnotetext{
${ }^{a}$ Department of Chemistry and Research Center for Materials Science, Nagoya University, Chikusa, Nagoya, 464-8602, Japan. E-mail: h_naka@nagoya-u.jp ${ }^{b}$ Department of Chemistry, University of Cambridge, Lensfield Road, Cambridge, CB2 1EW, UK. E-mail:aehw2@cam.ac.uk

$\dagger$ Electronic supplementary information (ESI) available. See DOI: 10.1039/ c6cy00899b
}

anes for applications in materials and biological sciences. ${ }^{4 g, 12}$ We here disclose that chitin-supported ruthenium nanoparticles (Ru/chitin) efficiently catalyze arene hydrogenation under aqueous conditions without hydrogenolyzing $\mathrm{C}-\mathrm{O} / \mathrm{C}-\mathrm{N}$ bonds at the benzylic positions.

In recent work we established that $\mathrm{Ru} /$ chitin serves as an efficient catalyst for the hydration of nitriles to amides under aqueous conditions. ${ }^{13,14}$ Based on this result, we reasoned that $\mathrm{Ru} /$ chitin should also be suited to the chemoselective hydrogenation of functionalized arenes because the nitrile hydration operated under near-neutral conditions ${ }^{13}$ and supported ruthenium nanoparticles are known to be good catalysts for arene hydrogenation. ${ }^{6,8 b, 9 a, b, 10 a-d, 15}$ As shown in Table 1, the activity of Ru was tested in the hydrogenation of benzyl glycidyl ether (1a) to cyclohexylmethyl glycidyl ether (2a). This reaction allowed the monitoring of both reactivity and selectivity for arene hydrogenation over hydrogenolysis at the benzylic position or acid-/base-mediated opening of the oxirane ring..$^{9,16}$ Currently known catalysts effective in this transformation are limited to just two tailor-made systems: Rh/CNF-T (rt, $12 \mathrm{~h})^{9 c}$ and Ru/HPS-NR ${ }_{3} \mathrm{Cl}\left(30{ }^{\circ} \mathrm{C}, 24\right.$ h). ${ }^{9 d, 17} \mathrm{Ru} /$ chitin can be prepared by simple impregnation-reduction using inexpensive $\mathrm{RuCl}_{3} \cdot 3 \mathrm{H}_{2} \mathrm{O}, \mathrm{NaBH}_{4}$ and commercially available chitin under aqueous conditions and in the absence of capping agents. ${ }^{13}$ Results demonstrate that the hydrogenation of $1 \mathrm{a}$ was effectively catalyzed by $\mathrm{Ru} /$ chitin. When a mixture of $1 \mathrm{a}(1.0 \mathrm{mmol}), \mathrm{H}_{2} \mathrm{O}(5 \mathrm{~mL})$ and $\mathrm{Ru} /$ chitin ( $0.8 \mathrm{wt} \%, 0.008 \mathrm{mmol}$ of $\mathrm{Ru}, 0.8 \mathrm{~mol} \% \mathrm{Ru}$ ) was stirred at 50 ${ }^{\circ} \mathrm{C}$ under $\mathrm{a}_{2}$ atmosphere (2 $\mathrm{MPa}$ ), the hydrogenation was completed within $1.5 \mathrm{~h}$ and cyclohexane $2 \mathrm{a}$ was obtained in $98 \%$ yield (Table 1, entry 1 ). ICP-AES on the Ru/chitin catalyst before and after the hydrogenation cycle established that only negligible leaching of $\mathrm{Ru}(4.2 \mathrm{ppm})$ took place during the catalytic test. The hydrogenation proceeded in water with no detectable loss of the $\mathrm{C}-\mathrm{O}$ linkages in the substrates, there being no appreciable formation of side products 3a-6a. This result was reproducible $\left({ }^{1} \mathrm{H}\right.$ NMR yields of $2 \mathrm{a}$ in separate runs: 97, 95 and 97\%). Product 2 a could be isolated in $84 \%$ 
Table 1 Hydrogenation of $1 \mathrm{a}$ to $2 \mathrm{a}^{a}$

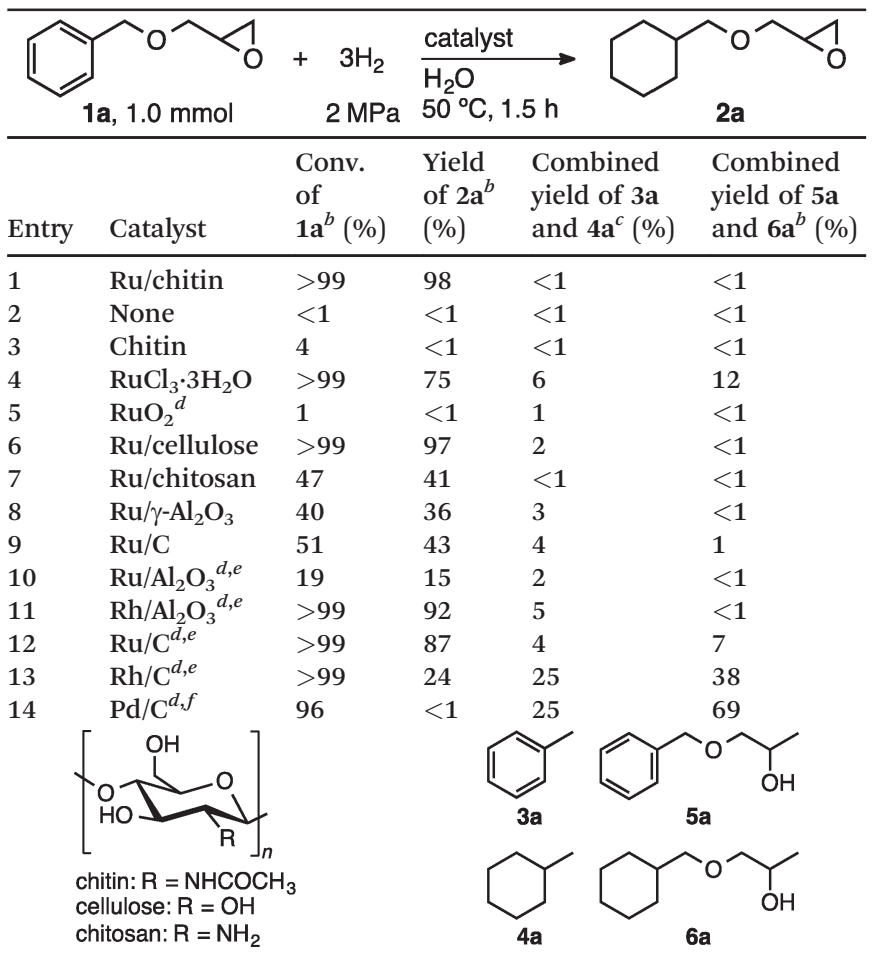

${ }^{a}$ Conditions: $1 \mathrm{a}(1.0 \mathrm{mmol})$, catalyst $(0.8 \mathrm{~mol} \% \mathrm{Ru})$ and $\mathrm{H}_{2} \mathrm{O}(5 \mathrm{~mL})$ at $50{ }^{\circ} \mathrm{C}$ for $1.5 \mathrm{~h}$ under $\mathrm{H}_{2}$ (2 MPa). ${ }^{b}$ Determined by ${ }^{1} \mathrm{H}$ NMR using mesitylene as an internal standard. ${ }^{c}$ GC-MS yield using $n$-octane as an internal standard. ${ }^{d}$ Purchased from commercial suppliers. ${ }^{e} 5$ wt $\%$ Ru or Rh. ${ }^{f} 10 \mathrm{wt} \%$ Pd.

yield after removal of the catalyst and $\mathrm{SiO}_{2}$ column chromatography, with $\mathrm{Ru}$ contamination proving lower than the detection limit of ICP-AES $(<1 \mathrm{ppb})$. Results demonstrate that both ruthenium and chitin were necessary for selective arene hydrogenation (entry 1 vs. entries 2-5). Moreover, heterogeneous catalysts prepared analogously to $\mathrm{Ru} /$ chitin but using cellulose, chitosan, $\gamma-\mathrm{Al}_{2} \mathrm{O}_{3}$ or carbon promoted arene hydrogenation but with lower selectivity (entries 6-9). Among these, hydrogenation with $\mathrm{Ru} /$ cellulose $^{15 c}$ was also found to be distinctly effective, although appreciable amounts of sideproducts were formed through hydrogenolysis (Table 1, entry 6). Results obtained using commercially available catalysts are summarized in entries $10-14 . \mathrm{Rh} / \mathrm{Al}_{2} \mathrm{O}_{3}$ (Sigma-Aldrich) proved efficient (2a: $92 \%$ yield) but induced partial hydrogenolysis to 3a or $4 \mathrm{a}$ (entry 11). Lastly, $\mathrm{Ru} / \mathrm{C}(\mathrm{TCI})^{18}$ was also a moderately good catalyst (2a: $87 \%$ yield) but caused competing epoxide ring-opening (entry 12$).{ }^{19}$

Results in Table 2 demonstrate that Ru/chitin-promoted selective arene hydrogenation was compatible with benzylic $\mathrm{C}-\mathrm{O}$ or $\mathrm{C}-\mathrm{N}$ linkages in alcohol, ether, amide and amino functionalities in a wide range of substrates $\left(\mathbf{1} \mathbf{b}-\mathbf{k}_{\mathrm{Na}}\right)$. The corresponding cyclohexanes $2 \mathbf{b}-\mathbf{k}_{\mathrm{Na}}$ were obtained in good-toexcellent isolated yields, with the products typically being isolated by distillation or column chromatography after simply removing the catalyst by filtration or centrifugation. Hydrogenation of significantly acid-sensitive benzyl alcohols $1 \mathrm{~d}$ and
Table 2 Catalytic hydrogenation of arenes (1) to cyclohexanes (2) with $\mathrm{Ru} /$ chitin $^{a}$

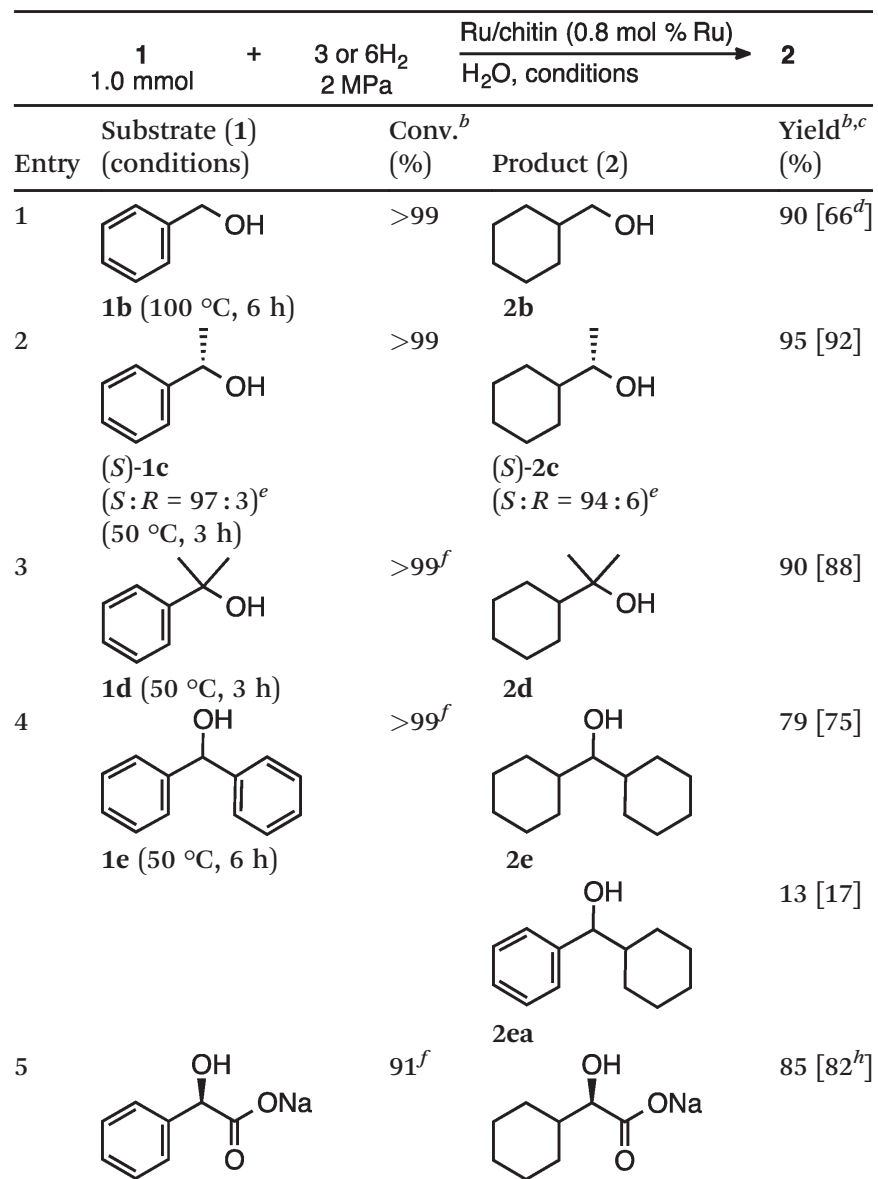

$(R)-1 \mathbf{f}_{\mathrm{Na}}$ $(S: R=1: 99)^{g}$

$\left(100{ }^{\circ} \mathrm{C}, 3 \mathrm{~h}\right)$

6<smiles>CC(=O)NCc1ccccc1</smiles>

$>99$

$(R)-2 \mathbf{f}_{\mathrm{Na}}$

$(S: R=1: 99)^{e}$<smiles>CC(=O)NCC1CCCCC1</smiles>

$99[93]$

$2 \mathrm{~g}$<smiles>O=C(NCc1ccccc1)c1ccccc1</smiles>
$>99$<smiles>O=C(NCC1CCCCC1)C1CCCCC1</smiles>
97 [95] 8 1h $\left(100{ }^{\circ} \mathrm{C}, 3 \mathrm{~h}\right)$<smiles>Cl[Mg]Cl</smiles>
1i· $\cdot \mathrm{HCl}\left(100{ }^{\circ} \mathrm{C}, 3 \mathrm{~h}\right)$ 9<smiles>C[C@H](N)c1ccccc1</smiles>
$>99$ $2 \mathrm{~h}$<smiles>NCC1CCCCC1</smiles>
93 [92] $2 \mathrm{i} \cdot \mathrm{HCl}$<smiles>C[C@H](NCCl)C1CCCCC1</smiles>
$96[91]$

$(S)-\mathbf{1 j} \cdot \mathbf{H C l}$

$(S: R=99: 1)^{e}$

$\left(100{ }^{\circ} \mathrm{C}, 3 \mathrm{~h}\right)$

10

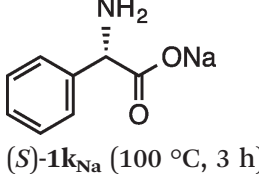

$(S)-2 \mathbf{j} \cdot \mathrm{HCl}$

$(S: R=96: 4)^{e}$<smiles>NC(C(=O)O[Na])C1CCCCC1</smiles> 
Table 2 (continued)

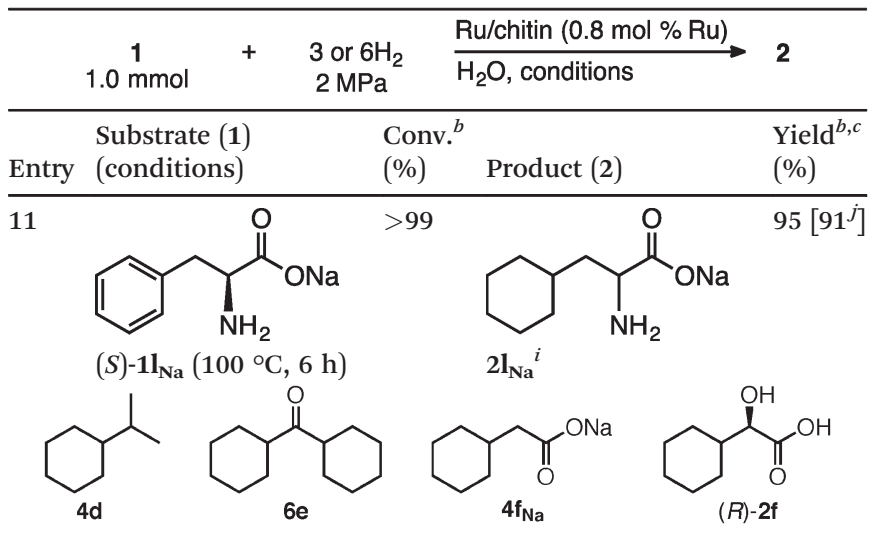

${ }^{a}$ Conditions: 1 (0.50 or $\left.1.0 \mathrm{mmol}\right), \mathrm{Ru} /$ chitin $(0.8 \mathrm{~mol} \% \mathrm{Ru}), \mathrm{H}_{2} \mathrm{O}(5$ $\mathrm{mL}$ ) and $\mathrm{H}_{2}$ (2 MPa). ${ }^{b}$ Determined by ${ }^{1} \mathrm{H}$ NMR using mesitylene as an internal standard. ${ }^{c}$ Isolated yield in parentheses. ${ }^{d}$ Low yield due to the volatile nature of the product. ${ }^{e}$ Absolute configuration and optical purity were determined by a polarimeter and chiral GC analyses. ${ }^{f}$ Side-products were detected: entry $3,4 \mathrm{~d}(3 \%)$; entry 4 , $6 \mathrm{e}$ $(7 \%)$; entry $5, \mathbf{4 f}_{\mathrm{Na}}(6 \%) .{ }^{g}$ As indicated by the supplier. ${ }^{h}$ Yield of carboxylic acid $(R)$-2f after the addition of $\mathrm{HCl}$ aq. ${ }^{i}$ Optical purity was not determined. ${ }^{j}$ Yield of $2 \cdot \mathrm{HCl}$ after the addition of $\mathrm{HCl}$ aq.

1e proceeded without loss of the $\mathrm{C}-\mathrm{O}$ bonds (Table 2, entries 3 and 4$).{ }^{20}$ Marginal amounts of side-products were detected when using $\mathbf{1 d}-\mathbf{f}_{\mathrm{Na}}$ (entries 3-5). The absolute configurations of $(S)-\mathbf{1 c},(R)-\mathbf{- 1} \mathbf{f}_{\mathrm{Na}}$ and $(S)-\mathbf{1} \mathbf{j} \cdot \mathbf{H C l}$ were retained under our reaction conditions (entries 2, 5 and 9). ${ }^{21}$ Unfortunately, double hydrogenation of dibenzyl ether or dibenzylamine.HCl was sluggish due to low reactivity and competitive hydrogenolysis at the benzylic positions. ${ }^{22}$ However, arene $\mathbf{1 h}$ could be doubly hydrogenated to give the dicyclohexyl analogue $2 \mathbf{h}$ in excellent yield (entry 7). By virtue of the aqueous conditions used, hydrophilic sodium carboxylates $\mathbf{1 f}_{\mathbf{N a}}$ and $\mathbf{1} \mathbf{k}_{\mathbf{N a}}$ as well as ammonium salts $\mathbf{1} \mathbf{i} \cdot \mathbf{H C l}$ and $\mathbf{1 j} \cdot \mathbf{H C l}$ could be effectively converted to give the corresponding salts of substituted cyclohexanes (entries 5, 8-10). In particular, the hydrogenation of $\mathbf{1} \mathbf{k}_{\mathrm{Na}}$ to $2 \mathbf{k}_{\mathrm{Na}}$ represents an important route for preparing nonstandard amino acid-bearing hydrophobic cyclohexyl rings from more accessible aromatic analogues. ${ }^{4 g, 12}$ In a similar vein, the hydrogenation of sodium phenylalanate $\left(\mathbf{1 l}_{\mathbf{N a}}\right)$ with $\mathrm{Ru} /$ chitin also gave the corresponding cyclohexyl-bearing amino acid $2 \mathbf{l}_{\mathrm{Na}}$ in high yield (entry 11 ). The substrate scope of other typical aromatic rings is summarized in Table S3. $\dagger$

The hydrogenation of toluene (3a) by $\mathrm{Ru} /$ chitin in water showed a turnover frequency (TOF) of $6000 \mathrm{~h}^{-1}$ and a turnover number (TON) of 3000 based on the amount of consumed $\mathrm{H}_{2}$ (eqn (1)). These values are higher than or comparable to those in previously reported hydrogenations of $\mathbf{3 a}$ in water with other $\mathrm{Ru}$ or $\mathrm{Rh}$ catalysts (Ru: TOF and TON, 10$2700 \mathrm{~h}^{-1}$ and 240-2700; Rh: $100-11000 \mathrm{~h}^{-1}$ and 300)..$^{4 e, 9 d, 10}$

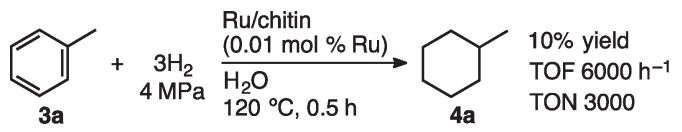

(a)
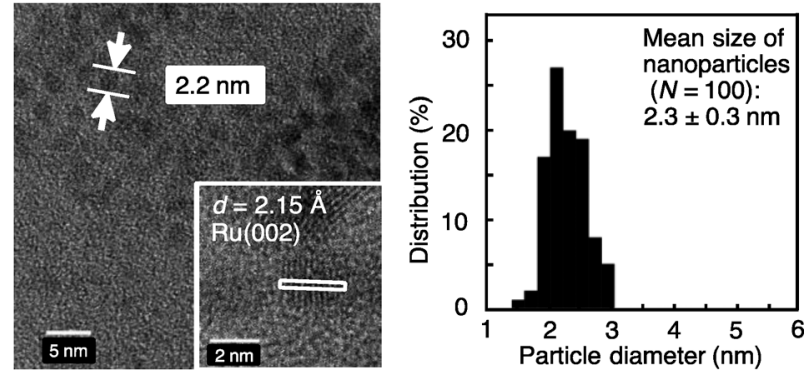

(b)
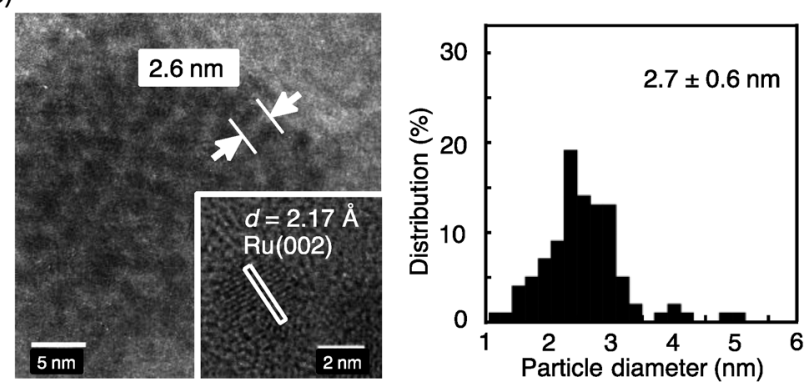

(c)
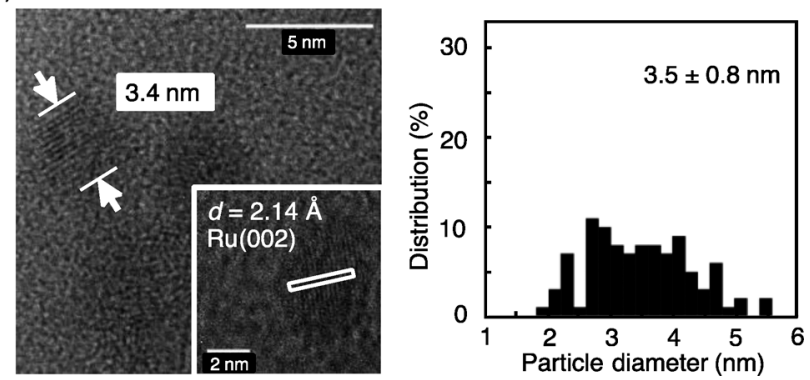

Fig. 1 TEM images and particle size distributions of Ru/chitin: (a) as prepared, (b) after 1 cycle and (c) after 6 cycles of hydrogenation of 1 a. 
contains comparably-sized nanoparticles, the selectivity is lower than Ru/chitin or Ru/cellulose (Fig. S8 and Table S5 $\dagger$ ).

In summary, we have prepared $2-3 \mathrm{~nm}$ chitin-supported ruthenium nanoparticles in the absence of additional capping agents. They have promoted efficient hydrogenation of arenes to cyclohexanes under near-neutral, aqueous conditions, with hydrogenation taking place to the exclusion of hydrogenolysis of normally reactive $\mathrm{C}-\mathrm{O}$ and $\mathrm{C}-\mathrm{N}$ linkages. Of importance, preliminary data point to the use of this readily available, environmentally benign support material being synonymous with the generation of nanoparticles whose dimensions provide both excellent conversion and selectivity. Ongoing work is seeking to more precisely investigate morphological changes exhibited by $\mathrm{Ru} /$ chitin in order to counteract the modest loss of activity after multiple hydrogenation cycles and to assess the possibility of developing these systems in a microfluidic context.

This work was financially supported by the Ichihara International Scholarship Foundation (to H. N.), the Institute for Quantum Chemical Exploration (to H. N.), MEXT (Japan) through its program "Integrated Research on Chemical Synthesis" (to H. N.) and the Royal Society through its International Exchange Scheme (to A. E. H. W. and H. N.). K. B. and B. R. K. thank the UK EPSRC (EP/J500380/1). Y. M. and A. M. acknowledge the IGER program at NU. We thank Professors R. Noyori (NU), S. Saito (NU) and K. Shimizu (Hokkaido U) for their helpful comments. Unprocessed data for this paper are available at the University of Cambridge data repository (see http://dx.doi.org/10.17863/CAM.432).

\section{Notes and references}

1 M. J. Palframan and A. F. Parsons, Product class 4: Five Membered and Larger-Ring Cycloalkanes, in Science of Synthesis, ed. H. Hiemstra, E. Schaumann and M. S. Baird, Thieme, Stuttgart, 2009, vol. 48, section 48.4, pp. 647-693.

2 (a) S. Nishimura, Hydrogenation of Aromatic Compounds, in Handbook of Heterogeneous Catalytic Hydrogenation for Organic Synthesis, John Wiley \& Sons, Inc., New York, 2001, ch. 11, pp. 414-496; (b) F. Foubelo and M. Yus, Reduction/ Hydrogenation of Aromatic Rings, in Arene Chemistry, ed. J. Mortier, John Wiley \& Sons, Inc., New Jersey, 2015, pp. 339364.

3 (a) H. Adkins and L. W. Covert, J. Phys. Chem., 1931, 35, 1684-1691; (b) Y. Takagi, T. Naito and S. Nishimura, Bull. Chem. Soc. Jpn., 1964, 37, 585-587.

4 Selective arene hydrogenation remains a major issue in current synthetic chemistry: (a) I. S. Park, M. S. Kwon, K. Y. Kang, J. S. Lee and J. Park, Adv. Synth. Catal., 2007, 349, 2039-2047; (b) R. Baumgartner, G. K. Stieger and K. McNeil, Environ. Sci. Technol., 2013, 47, 6545-6553; (c) C. MorenoMarrodan, F. Liguori, E. Mercadé, C. Godard, C. Claver and P. Barbaro, Catal. Sci. Technol., 2015, 5, 3762-3772; (d) W. Gu, M. M. Stalzer, C. P. Nicholas, A. Bhattacharyya, A. Motta, J. R. Gallagher, G. Zhang, J. T. Miller, T. Kobayashi, M. Pruski, M. Delferro and T. J. Marks, J. Am. Chem. Soc.,
2015, 137, 6770-6780; (e) C.-H. Pélisson, A. DenicourtNowicki and A. Roucoux, ACS Sustainable Chem. Eng., 2016, 4, 1834-1839; $(f)$ M. M. Stalzer, C. P. Nichloas, A. Bhattacharyya, A. Motta, M. Deferro and T. J. Marks, Angew. Chem., Int. Ed., 2016, 55, 5263-5267; $(g)$ B. Sun and G. SüssFink, J. Organomet. Chem., 2016, 812, 81-86.

5 (a) S. Nishimura, Bull. Chem. Soc. Jpn., 1959, 32, 1155-1157; (b) P.-E. Tong, P. Li and A. S. C. Chan, Tetrahedron: Asymmetry, 2001, 12, 2301-2304; (c) S. Nishimura and $\mathrm{H}$. Taguchi, Bull. Chem. Soc. Jpn., 1963, 36, 353-355.

6 (a) Y. Takagi, T. Naito and S. Nishimura, Bull. Chem. Soc. Jpn., 1964, 37, 585-587; (b) Z. Tang, Z. Yang, X. Chen, L. Cun, A. Mi, Y. Jiang and L. Gong, J. Am. Chem. Soc., 2005, 127, 9285-9289.

7 (a) J. H. Stocker, J. Org. Chem., 1962, 27, 2288-2289; (b) S. Siegel, Rhodium on Alumina, in Encyclopedia of Reagents for Organic Synthesis, ed. L. A. Paquette, D. Crich, P. L. Fuchs and G. A. Molander, Wiley, Chichester, 2009, vol. 11, pp. 8559-8563; (c) F. Jing, M. R. Smith III and G. L. Baker, Macromolecules, 2007, 40, 9304-9312.

8 (a) I. S. Park, M. S. Kwon, K. Y. Kang, J. S. Lee and J. Park, Adv. Synth. Catal., 2007, 349, 2039-2047; (b) H.-W. Lin, C. H. Yen and C.-S. Tan, Green Chem., 2012, 14, 682-687.

9 (a) Y. Motoyama, M. Takasaki, K. Higashi, S.-H. Yoon, I. Mochida and H. Nagashima, Chem. Lett., 2006, 35, 876-877 (CNF-P = platelet carbon nanofibers); (b) M. Takasaki, Y. Motoyama, K. Higashi, S.-H. Yoon, I. Mochida and H. Nagashima, Chem. - Asian J., 2007, 2, 1524-1533; (c) Y. Motoyama, M. Takasaki, S.-H. Yoon, I. Mochida and H. Nagashima, Org. Lett., 2009, 11, 5042-5045 (CNF-T = tubular carbon nanofibers); (d) L. Gao, K. Kojima and $\mathrm{H}$. Nagashima, Tetrahedron, 2015, 71, 6414-6423 (HPS-NR3Cl = ammonium salts of hyperbranched polystyrene).

10 For examples of $\mathrm{Ru}$ or $\mathrm{Rh}$ nanoparticle catalysts for arene hydrogenation in water, see: Ru: (a) A. Nowicki, Y. Zhang, B. Léger, J.-P. Rolland, H. Bricout, E. Monflier and A. Roucoux, Chem. Commun., 2006, 296-298; (b) A. Nowicki, V. Le Boulaire and A. Roucoux, Adv. Synth. Catal., 2007, 349, 2326-2330; (c) L. Song, X. Li, H. Wang, H. Wu and P. Wu, Catal. Lett., 2009, 133, 63-69; (d) C. Hubert, A. DenicourtNowicki, A. Roucoux, D. Landy, B. Leger, G. Crowyn and E. Monflier, Chem. Commun., 2009, 1228-1230; Rh: (e) C. Hubert, A. Denicourt-Nowicki, J.-P. Guégan and A. Roucoux, Dalton Trans., 2009, 7356-7358; $(f)$ C. Hubert, A. DenicourtNowicki, P. Beaunier and A. Roucoux, Green Chem., 2010, 12, 1167-1170; $(g)$ E. G. Bilé, R. Sassine, A. Denicourt-Nowicki, F. Launay and A. Roucoux, Dalton Trans., 2011, 40, 6524-6531.

11 During the review process for this manuscript, arene hydrogenation of benzyl ethers by the $\mathrm{Ru}$ /carbon-nitrogen matrix was reported: X. Cui, A.-E. Surkus, K. Junge, C. Topf, J. Radnik, C. Kreyenschulte and M. Beller, Nat. Commun., 2016, 7, 11326.

12 (a) P. J. Corringer, J. H. Weng, B. Ducos, C. Durieux, P. Boudeau, A. Bohme and B. P. Roques, J. Med. Chem., 1993, 36, 166-172; (b) R. Hartung, F. Hitzel-Zerrahn, T. Müller and J. Pietsch, US Pat., 8148430B2, 2012; (c) D. J. Ager and I. Prakash, Org. Process Res. Dev., 2003, 7, 164-167. 
13 A. Matsuoka, T. Isogawa, Y. Morioka, B. R. Knappett, A. E. H. Wheatley, S. Saito and H. Naka, RSC Adv., 2015, 5, 12152-12160.

14 Chitin is the second most abundant polysaccharide in nature: Chitin: Formation and Diagenesis, ed. N. S. Gupta, Springer, New York, 2011.

15 (a) L. M. Rossi and G. Machado, J. Mol. Catal. A: Chem., 2009, 298, 69-73; (b) F. Schwab, M. Lucas and P. Claus, Angew. Chem., Int. Ed., 2011, 50, 10453-10456; (c) M. Kaushik, H. M. Friedman, M. Bateman and A. Moores, RSC Adv., 2015, 5, 53207-53210; (d) A. Gual, C. Godard, S. Castillon and C. Claver, Dalton Trans., 2010, 39, 11499-11512; (e) P. Lara, K. Philippot and B. Chaudret, ChemCatChem, 2013, 5, 28-45.

16 2a can also be a (co-)monomer for preparing epoxide resins.

17 (a) Ref 9c: 1a (0.5 mmol), Rh/CNF-T (10 mg, $0.2 \mathrm{wt} \% \mathrm{Rh}, 0.04$ mol\% Rh), $\mathrm{H}_{2}$ (1 MPa), $n$-hexane (1 mL), rt, $12 \mathrm{~h} ; 2 \mathrm{a},>99 \%$ yield; (b) Ref 9d: 1a (1 mmol), Ru/HPS-NR ${ }_{3} \mathrm{Cl}(0.3 \mathrm{~mol} \% \mathrm{Ru})$, $\mathrm{H}_{2}$ (3 MPa), $\mathrm{H}_{2} \mathrm{O}(1 \mathrm{~mL}), 30{ }^{\circ} \mathrm{C}, 24 \mathrm{~h}$; 2a, 96\% yield.

$18 \mathrm{Ru} / \mathrm{C}$ and $\mathrm{Rh} / \mathrm{C}$ are excellent, general catalysts for arene hydrogenation: T. Maegawa, A. Akashi, K. Yaguchi, Y. Iwasaki, M. Shigetsura, Y. Monguchi and H. Sajiki, Chem. Eur. J., 2009, 15, 6953-6963.

19 The origin of high selectivity in the hydrogenation of 1a with $\mathrm{Ru} /$ chitin remains unclear. Coordination of hydroxyl groups in chitin to the Ru metal does not seem to suppress catalytic activity for side reactions; the selectivity in the hydrogenation with $\mathrm{Rh} / \mathrm{Al}_{2} \mathrm{O}_{3}, \mathrm{Ru} / \mathrm{C}$ or $\mathrm{Rh} / \mathrm{C}$ was not significantly altered by adding ethylene glycol (Table $\mathrm{S} 2, \uparrow$ entries 1-3). Meanwhile, the coordination of acetamide groups to the $\mathrm{Ru}$ metal may partly account for the high selectivity of $\mathrm{Ru} /$ chitin; addition of $\mathrm{N}$-acetylethanolamine increased the selectivity for arene hydrogenation with $\mathrm{Rh} / \mathrm{C}$ (Table S2, $\dagger$ entry 5).

20 T. L. Amyes, J. P. Richard and M. Novak, J. Am. Chem. Soc., 1992, 114, 8032-8041.

21 The reason for a small amount of racemization in Table 2, entries 2 and 9 is not entirely clear, but we assume it to result from dehydrogenation of alcohol or amine. $\mathrm{HCl}$ followed by hydrogenation of the resulting ketones and iminium salts. This view is based on the following observations: (1) in Table 2, entry 4 , ketone $6 \mathrm{e}$ formed in $7 \%$ yield; (2) hydrogenation of acetophenone with $\mathrm{Ru} / \mathrm{chitin}$ under the standard conditions yielded cyclohexyl methyl ketone (20\%), 1c (27\%) and 2c (52\%).

22 Hydrogenation of dibenzyl ether $\left(100{ }^{\circ} \mathrm{C}, 6 \mathrm{~h}, 91 \%\right.$ conv. gave a mixture of bis(cyclohexylmethyl) ether (27\%), benzyl cyclohexylmethyl ether (38\%), 2 b (7\%) and other unidentified products. Hydrogenation of dibenzylamine $\cdot \mathrm{HCl}$ $\left(100{ }^{\circ} \mathrm{C}, \quad 5 \mathrm{~h},>99 \%\right.$ conv.) gave a mixture of bis(cyclohexylmethyl)amine $\cdot \mathrm{HCl}(21 \%)$ and $2 \mathbf{i} \cdot \mathrm{HCl}(74 \%)$. 